\title{
3D GEOMATICS TECHNIQUES FOR AN INTEGRATED APPROACH TO CULTURAL HERITAGE KNOWLEDGE: THE CASE OF SAN MICHELE IN ACERBOLI'S CHURCH IN SANTARCANGELO DI ROMAGNA
}

\author{
G. Bitelli ${ }^{\text {a, }}$, M. Dellapasqua ${ }^{\text {a }}$, V.A. Girelli ${ }^{\text {a }}$, E. Sanchini ${ }^{\text {b }}$, M.A. Tini ${ }^{\text {a }}$ \\ a DICAM, Dept. of Civil, Chemical, Environmental and Material Engineering, University of Bologna, Italy - (gabriele.bitelli, \\ mirko.dellapasqua, valentina.girelli, mariaalessandra.tini)@unibo.it \\ b elisabetty89@gmail.com
}

KEY WORDS: Terrestrial Laser Scanner, Photogrammetry, Structure from Motion, Historical Building Information Modelling

\begin{abstract}
:
The modern Geomatics techniques, such as Terrestrial Laser Scanner (TLS) and multi-view Structure from Motion (SfM), are gaining more and more interest in the Cultural Heritage field. All the data acquired with these technologies could be stored and managed together with other information in a Historical Building Information Model (HBIM).

In this paper, it will be shown the case study of the San Michele in Acerboli's church, located in Santarcangelo di Romagna, Italy. This church, dated about the 6th century A.D., represents a high relevant Romanic building of the high Medieval period. The building presents an irregular square plan with a different length of the lateral brick walls and a consequential oblique one in correspondence of the apse. Nevertheless, the different lengths of the lateral brick walls are balanced thanks to the irregular spaces between the windows. Different changes occurred during the centuries, such as the closing of the seven main doors and the building of the bell tower, in the 11th century A.D., which is nowadays the main entrance of the church.

An integrated survey was realized, covering the exterior and the interior. The final 3D model represents a valid support not only for documentation, but also to maintain and manage in an integrate approach the available knowledge of this Cultural Heritage site, developing a HBIM system in which all the mentioned historical, geometrical, material matters are collected.
\end{abstract}

\section{INTRODUCTION}

Nowadays, BIM (Building Information Modeling) is getting more and more influence in the AEC (Architecture, Engineering and Construction) sector to collect and integrate each other several kinds of information. Therefore, it's easy to understand the power of this approach to generate a shared knowledge system able to involve at the same time all the technical figures involved during the whole lifecycle of the building. In fact, BIM is a digital representation of a building, which includes a shared database of all the aspects and information concerning a building, such as the geometrical and material issues, the time scheduling, the maintenance and so on until the demolition phase.

If these aspects can be easily applied for new buildings, an open challenge concerns the application of this approach to the existing ones. This challenge is also harder when we talk about Cultural Heritage and historical buildings. In fact, these objects were often manipulated during the centuries, with demolitions, reconstructions and collected, layer after layer, dissimilar styles. Furthermore, also their maintenance status and deformation are to be considered and managed.

The conservation of ancient buildings, mainly due to their high relevant heritage evidence, is frequently a critical point in the Italian context. In fact, recent events, such as the earthquake involving the centre of Italy, made clear the need of a capillary system of knowledge for the management of these aspects and for an efficient development of restoration and conservation activities (Oreni et al., 2014). The international scientific community introduced the concept of HBIM (Historical
Building Information Modeling). Originally, the term HBIM was used as "a novel prototype library of parametric objects, based on historic architectural data, in addition to a mapping system for plotting the library objects onto laser scan survey data" (Murphy et al., 2013).

It clearly emerges the need to have some geometrical and radiometric data to support the modelling phase of the process, and some modern Geomatics techniques can offer a solid support for this purpose. Terrestrial Laser Scanner (TLS) and multi-view Structure from Motion (SfM) techniques can for example generate high fidelity point clouds, which represent the monument inspected (Remondino, 2011; Chiabrando et al., 2016).

In this work, we will discuss the application of these aspects in a case study referred to the San Michele in Acerboli's church in Santarcangelo di Romagna, near Rimini, Italy. This church is a peculiar mixture of both simplicity and refinement. It also represents one of the most relevant and representative architecture of the high medieval period in the Rimini area.

The modern Geomatics techniques can represent the first step to obtain the right $3 \mathrm{D}$ abstraction of the reality and a solid support to develop a BIM model (Dore \& Murphy, 2012). In this case, the BIM model has been developed by using the commercial software Autodesk Revit 2017, a widely-used tool able to work with point clouds coming from TLS and SfM, to manage the information in order to develop and obtain an appropriate model.

At last, an evaluation of the HBIM model's accuracy will be conducted by using a free software (Quattrini et al., 2015).

* Corresponding author 
Furthermore, this step will allow us to determine also the deviation from the verticality that involves the façade.

\section{SAN MICHELE IN ACERBOLI'S CHURCH: A CASE STUDY FOR CULTURAL HERITAGE}

\subsection{Origin of the church and historical background}

The San Michele in Acerboli's church is one of the most significant and ancient examples of early medieval religious architecture in Rimini.

The church is located in the south of the old town of Santarcangelo di Romagna, in a flat area inhabited since Roman times. The large quantity of archaeological finds discovered near the church, suggests that the site was originally occupied by many Roman handicraft factories producing bricks, pots and furniture for domestic and agricultural uses.

Even though many researchers examined the history of the church and found it difficult to date, the origins of the building probably date back to the half of $6^{\text {th }}$ century. The construction of San Michele in Acerboli fits into a specific architectural context, dating back to the time when Ravenna was under the power of Justinian (Byzantine emperor from 527 to 565).

The San Michele's church is an ancient type of holy Christian building, called Pieve (from the Latin word "plebs" that means mob), widespread since the half of $6^{\text {th }}$ century in the rural areas ruled by the Church of Ravenna (Lombardini, 2002).

These churches were originally built to directly manage the plots of land assigned to families, who cultivated them for the Church in exchange for payment of a rent.

In addition to economic and administrative functions, the rural churches were also places of dissemination of the culture and Christian religion.

These primitive churches were usually built near existing pagan temples, the remains of which were often reused for the construction of the new Christian sacred buildings.

Although the San Michele in Acerboli origins are quite humble, its refined architectural and decorative motifs refer to the historical context of its construction epoch: the architecture represented a symbol of power, characterized by sumptuous and elegantly decorated buildings.

\subsection{Architectural description}

The church looks like an entirely bricks made and quite sober building; the original masonry is made with a large and thin kind of bricks, called "giulianei" $(4 \times 42 \times 28 \mathrm{~cm})$, often used by Byzantine builders during the reign of Giustiniano (Mazzotti, 1961).

The church presents only one nave and a quite irregular plan with the slightly oblique rightward façade: according to some researchers, this is a trick to make up the human eye's tendency to perceive with more strength the elements placed on the right (Russo, 1983).

The internally circular and externally polygonal apse is directed eastward, towards the rising sun, the symbol of the coming of Christ. The apse masonry, highly irregular at the bottom, obtained with resulting material and pebbles, suggests that it originally belonged to an older building, incorporated into the new construction in its lower part (Mazzotti, 1961).

The Romanesque square bell tower, added later, during the $11^{\text {th }}$ century, is located oddly leaning against the façade, to ensure greater stability to the structure. The bell tower is the church entrance hall, the floor of which is lower than the ground level.
Along the building's walls there are nineteen large round arched windows (eight in each long side and three in the apse) and seven ancient and still walled doors.

Non-plastered internal walls are only marked by the alternation of windows and doors walled profiles.

The openings arrangement (mutual distance and size) has been designed to improve the visual perception and the interior lighting. The Byzantine designer has ordered the openings with different criteria on each masonry wall to create the illusion of equal length of the sides (Russo, 1983). The wooden trussed ceiling and the terracotta tiled floor are not the original ones.

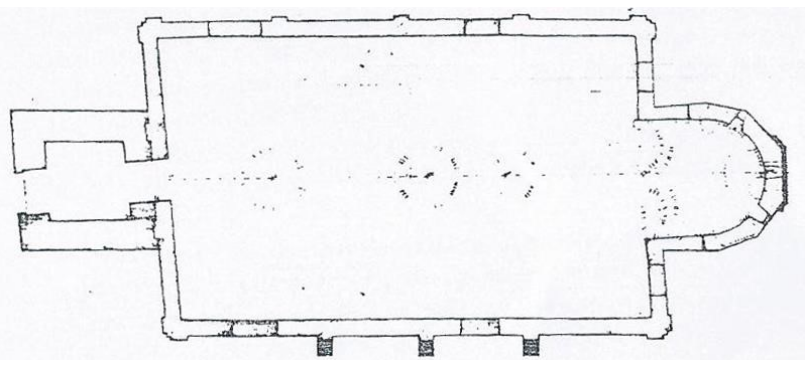

Figure 1. Illustration of the irregular plan of the church (Mazzotti, 1961).
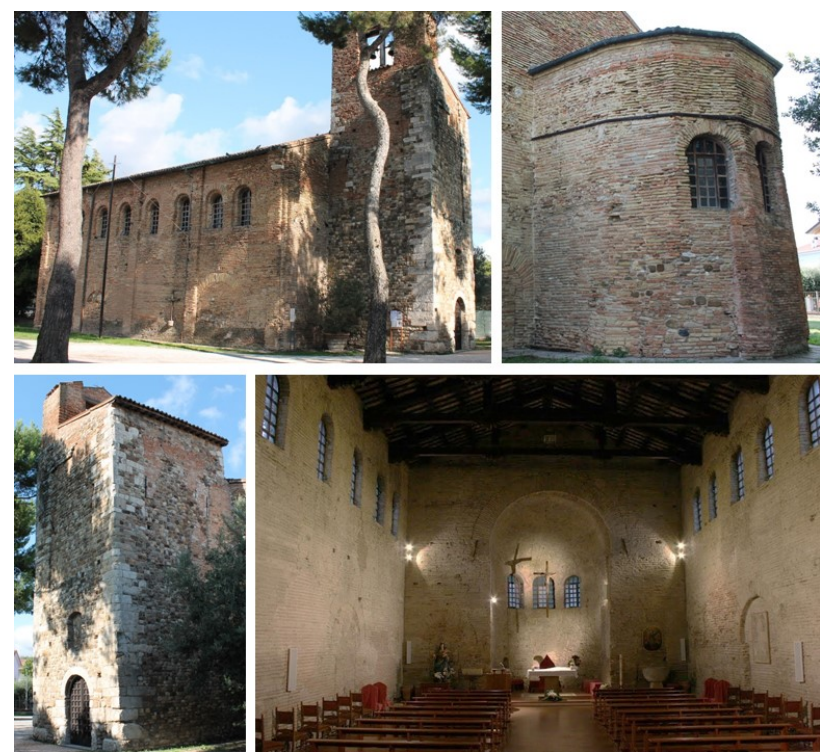

Figure 2. Photos of the outdoor and indoor of the church.

\subsection{Historical evolution}

Like other religious buildings of the same historical period, the San Michele church is characterized by two distinct construction phases. The edification of the church, dating back half of $6^{\text {th }}$ century during the Justinian era, was designed by an unknown Byzantine architect. The successive edification of the bell tower and the crypt chapel below the apse area is dating back the $10^{\text {th }}$ or $11^{\text {th }}$ century.

During the $20^{\text {th }}$ century, the church has undergone several restorations (from the year 1912 to 1969) to repair the war damage and the general state of decay: masonries and roof were repaired and the original windows, walled at the time, were restored. 
In 1913, the archaeological excavations in the area below the apse and the front of the nave began and the remains of the crypt were found.

Despite the importance of the structure, no detailed geometric surveys existed so far. The work presents a complete survey conducted by different techniques with the aim to provide a detailed 3D database, to support an HBIM experience and other information data management.

\section{THE 3D SURVEY: FROM REALITY TO A COMPLETE POINT CLOUD MODEL}

The survey of the whole church was conducted with an integrated approach, in which a classical topographic survey with a Total Station has supported modern Geomatics techniques, such as the Terrestrial Laser Scanner (TLS) and the multi-view Structure from Motion (SfM).

Firstly, through a survey by total station, performed with a Leica TS30, the 3D coordinates of some artificial targets, placed externally and internally the church, were calculated. This choice permitted the establishment of a unique local reference system for the whole building model, with $\mathrm{Z}$ axis along the vertical. Furthermore, it allowed an easy and robust subsequent registration of all the point clouds, generated by TLS and SfM.

The RIEGL VZ400 instrument, equipped with the calibrated digital camera Nikon D90 for the RGB information, performed the TLS survey of the external and internal portions of the church. To cover the whole monument, 51 point clouds were acquired from 12 scan positions for the exterior and 12 for the interior of the church, distributed as shown in figure 3. In particular, from some points of view it was necessary to tilt the instrumental axis at various inclinations, to survey the highest parts of the building as ceiling and vaults (Figure 4).

All the scans were aligned by using the high reflectance targets acquired with the total station survey, obtaining a unique point cloud characterized by $3-4 \mathrm{~mm}$ density.

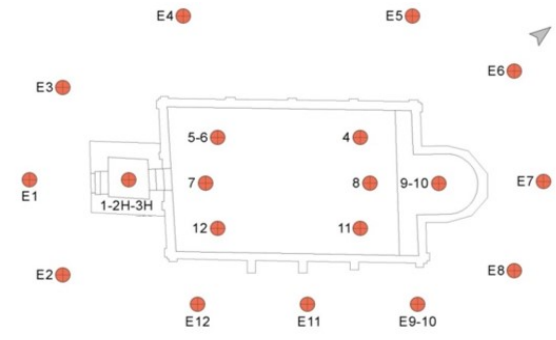

Figure 3. The TLS acquisition scheme; red dots indicate the scan positions.

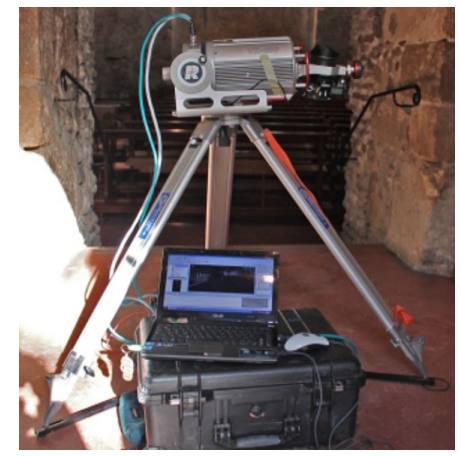

Figure 4. The laser scanner with horizontal inclination of the instrumental axis in the church entrance hall.
The SfM survey, useful to reconstruct the roof of the church, has been conducted by using a DSLR full-frame camera Canon EOS 6D, and an extendable telescopic tripod, able to grow up till to 13 metres (Figure 5). A considerable number of images (209), variously oriented, were acquired to obtain a complete model of the roof.

The photogrammetric reconstruction process was conducted with the commercial software Photoscan, from Agisoft. Also in this case, the same targets used during the total station and TLS surveys were adopted to georeference the final 3D model.
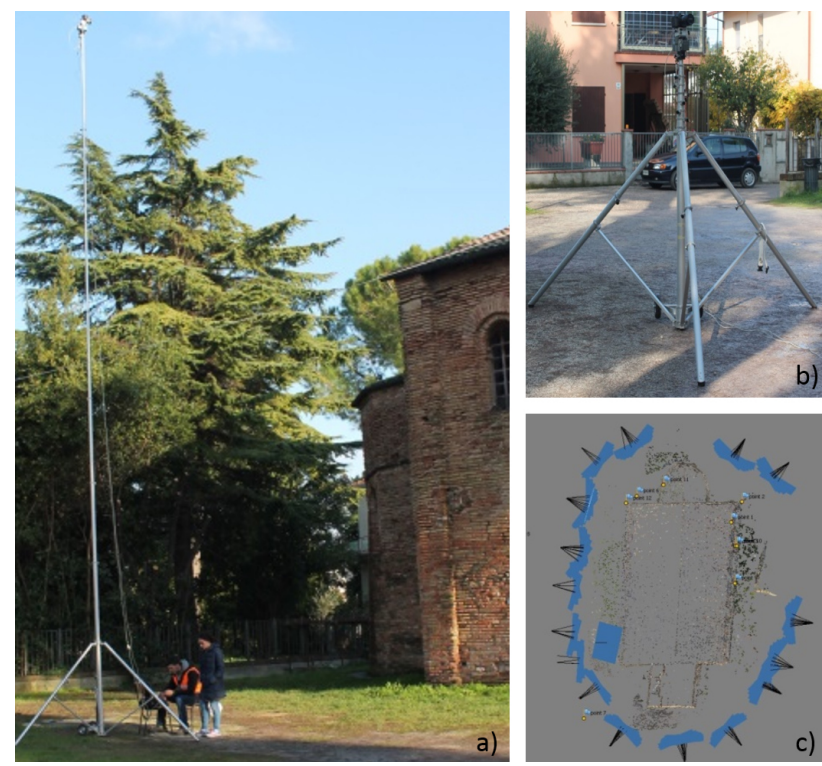

Figure 5. The photogrammetric survey of the church roof; a) and b) equipment used for the images acquisition,

c) reconstruction of exterior orientation after the images alignment phase in the SfM processing.

The two models obtained with the TLS and SfM surveys have been aligned and merged in a commercial software for the processing of $3 \mathrm{D}$ data; the integration of the techniques permitted to fill the lacks present in the single products.

The result of all the surveys is a complete, high dense and accurate point cloud representing the church's geometry. The final model counts about 87 millions of points for the exterior and 80 millions of points for the interior. Overall, the spacing between points is varying between 2 and 4 millimetres.
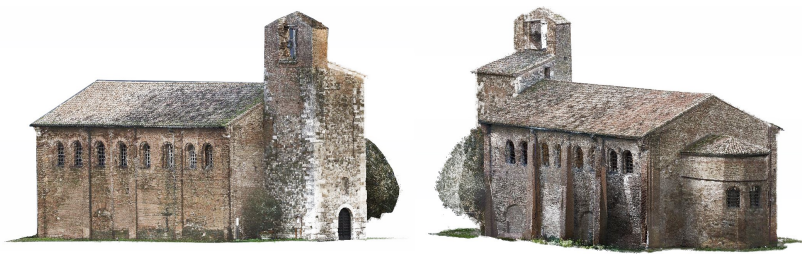

Figure 6. Different views of the final point cloud of the exterior of the church.

Due to some problems with the light conditions inside the building, it was decided to artificially colour the internal point cloud with a grey scale, by using the Portion de Ciel Visible (PCV) plugin in the CloudCompare software. This plugin calculates the illumination of a point cloud as if the light was coming from a theoretical hemisphere or sphere around the 
object, allowing to emphasize the geometrical discontinuities (figure 7)

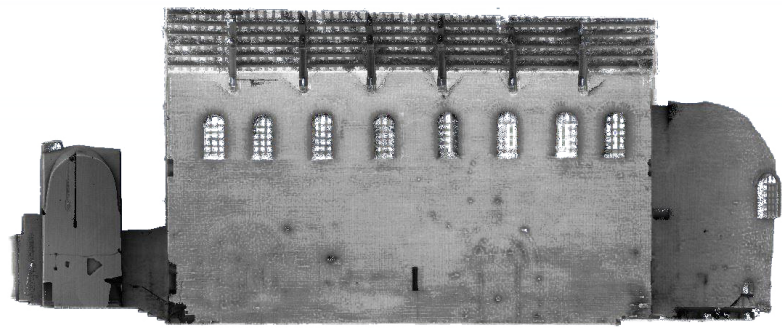

Figure 7. The point cloud representing the interior of the Church, coloured by using the PCV algorithm.

The 3D point cloud, accurately reproducing the building geometry, permits to analyse it in every detail and characteristic, also noting the irregularities. In the case study, the model highlights an irregular plan with a non-perpendicular angle between the walls and a great deformation occurred at the East façade. The last was used to evaluate the reliability of the HBIM model.

\section{HBIM DEVELOPMENT AND VALIDATION}

\subsection{The development of an HBIM}

The complete point cloud representing the San Michele in Acerboli's church was finally used for a first development of a HBIM model, where all the relevant information connected to the building (historical, materials, constructive techniques, etc.) could be stored and georeferenced. The commercial software Autodesk Revit 2017 was adopted for this purpose.

The final goal was the efficiency evaluation of the tools directly offered by the software to develop an HBIM of such an irregular brick wall monument, and to compare it with the point clouds acquired. It is important to notice how the modelling of this kind of buildings presents many difficulties, mainly concerning the great vertical and horizontal irregularities involving the structure.

In fact, a BIM developed in a preliminary design phase does not need to consider these aspects and these irregularities. It is possible to represent its portions with some approximate and idealized entities, such as regular walls, roofs, plants and so on. Anyway, these considerations are not applicable in a modeling phase concerning an existing building as irregular as the San Michele's church.

Therefore, the challenge was to achieve a satisfying geometrical representation of this church, focusing its evaluation on the east façade, which presents a great deviation from the ideal vertical plan.

As known, there are many commercial and few free plug-ins (Garagnani \& Manfredini, 2013) able to work with the point cloud in Revit and to extract features. In this case, we tried to develop an accurate and a high-fidelity model by using the tools offered by the software only and in the fewest possible steps (Quattrini, 2015).

To do so, we firstly needed to reduce the point cloud to easily manage the great amount of data. We decided to decimate the complete point cloud adopting $1 \mathrm{~cm}$ as spacing between the points. This reduced point cloud was successively imported in the software Autodesk Recap and converted in the .rcp format for the importing in Revit.
Finally, the modeling phase in Revit started, mainly by the use of the mass modeling tool to generate the masses able to represent the geometry of the building with all its irregularities. The use of this tool, normally adopted during a preliminary and conceptual design phase, is a fast way to draw the volumes representing the church, on which directly apply all the families. This procedure was conducted in the mass modeling environment inside Revit. In this environment, we directly and manually drew on the point cloud the main reference lines able to correctly represent the church. Focusing on the nave, in Figure 8 is shown the mass representing this part of the church.

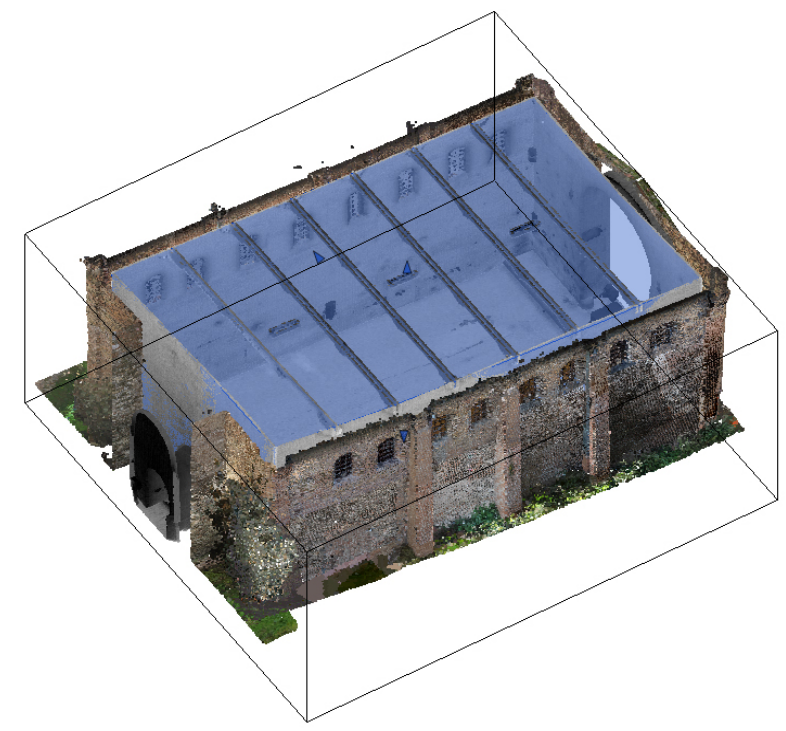

Figure 8 . The mass of the nave.

Starting from this mass, the transition between the generical mass trough the building model was possible converting its faces into the components, the so-called Revit families, such as the walls, the floors and the roofs. This step was performed using both the parametric elements already in the Revit internal library and some external families imported into the model. Moreover, the most complex elements, such as the pilasters and the buttresses, were directly modelled in place by using the BRep operations, such as extrusion and so on, to obtain a high fidelity geometrical representation.

It is also important to notice and highlight how, in a genuine BIM approach, the volumes and the floor areas of the masses are also able to be automatically extracted, put into abacuses and immediately updated after every model modification.

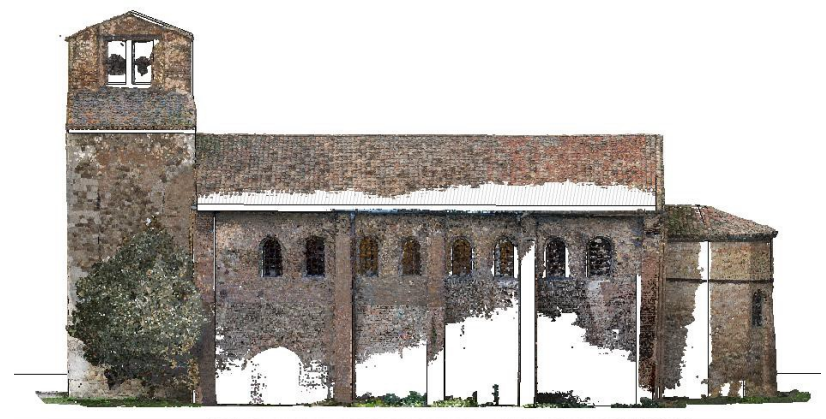

Figure 9. The East façade of the Church. 
Finally, the result was the entire HBIM, developed in the Revit environment, of the whole church. As said, this model takes in account all the irregularities involving the structure.

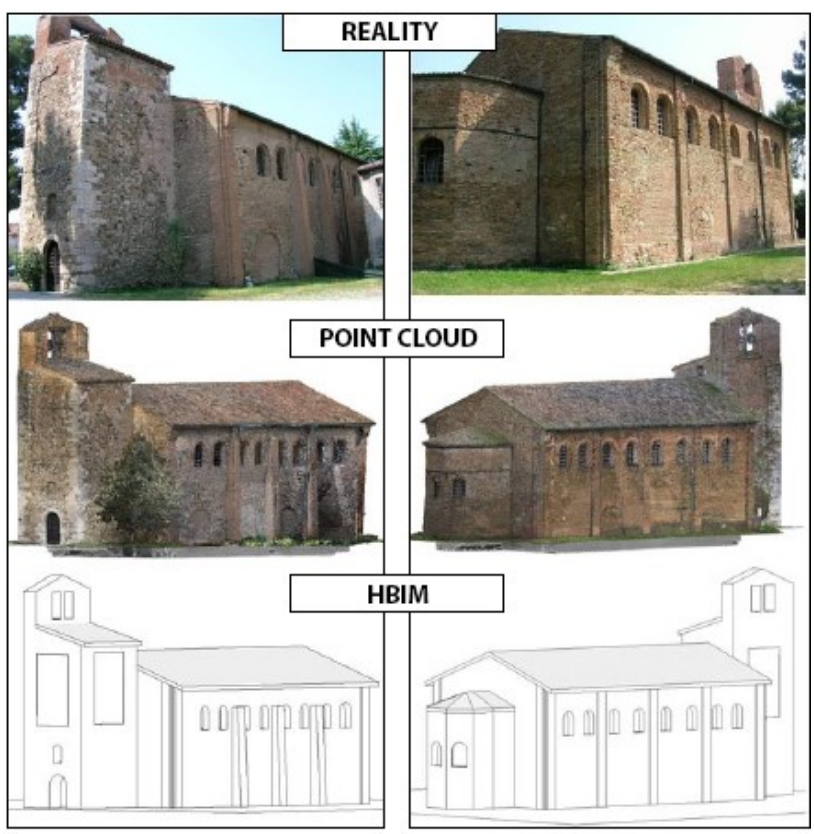

Figure 10. The distinct phases: from the reality to an HBIM, through a point cloud resulting from the $3 \mathrm{D}$ integrated survey.

\subsection{The evaluation of the HBIM model for the Eastern façade of the Church}

The evaluation of the model was mainly conducted on the most not-vertical façade of the building, the Eastern one (Figure 11). For this portion were compared the point cloud, considered like a reference, and the HBIM model (Figure 12). Furthermore, a second comparison was realized between the same point cloud and a simplified HBIM, which did not consider the irregularities of the structure and presents simple vertical walls (Figure 14).

This part was conducted using the mentioned CloudCompare open source software, exporting the mesh of HBIM façades from Revit in .obj format.
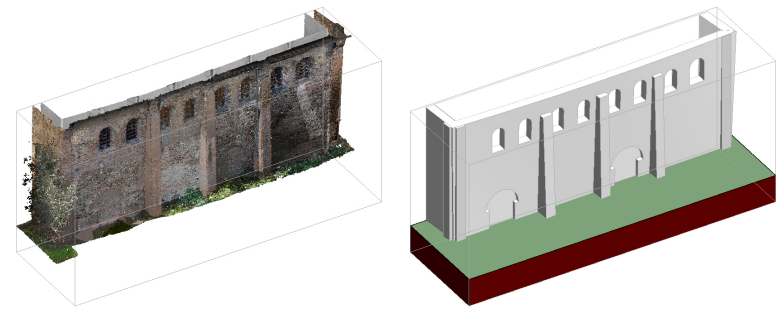

Figure 11. The portion of the point cloud and the portion of the HBIM considered.

The first comparison, the one between the point cloud (about 3 million points) and the HBIM, shows the quality of this model, well representing the real condition of the façade. The Figure 12 , visually presenting the difference between the two datasets, clearly permits to assume this model as a good and reliable representation of the façade. There are only some dissimilarities in correspondence of some architectonical peculiarities. One of these peculiarities refers, for example, to a brick adornment in correspondence of the left buttresses, presenting a local high deviation highlighted from the red colour in Figure 12.

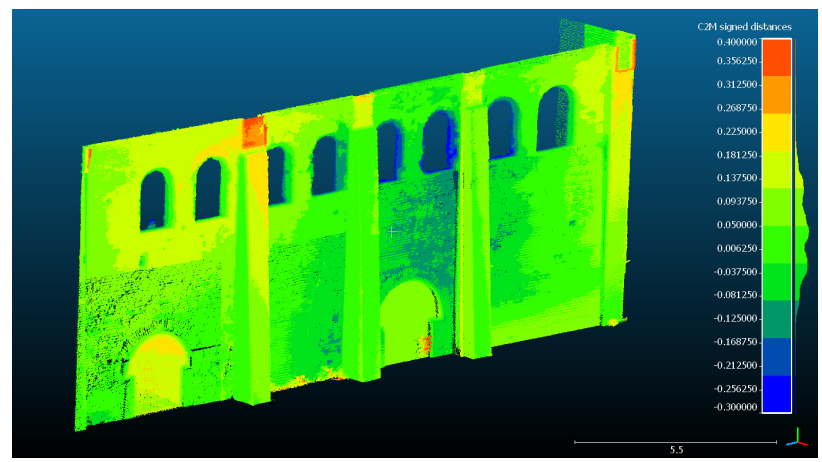

Figure 12. The first comparison: the HBIM façade versus the point cloud.

The development of an external and exhaustive library useful for these objects will permit to manage and represent these architectural peculiarities in an effortless and speedy way and to obtain better results.

One of the main difficulties on the management of this façade concerned the presence of a double curvature in the wall. This aspect causes much more difficulties mainly to insert the socalled Revit families.

At last, an additional analysis permitted to show the average distance between the two entities (Figure 13). This value, about $6 \mathrm{~cm}$, is a satisfying result that confirm the good similarity gained with this kind of approach.

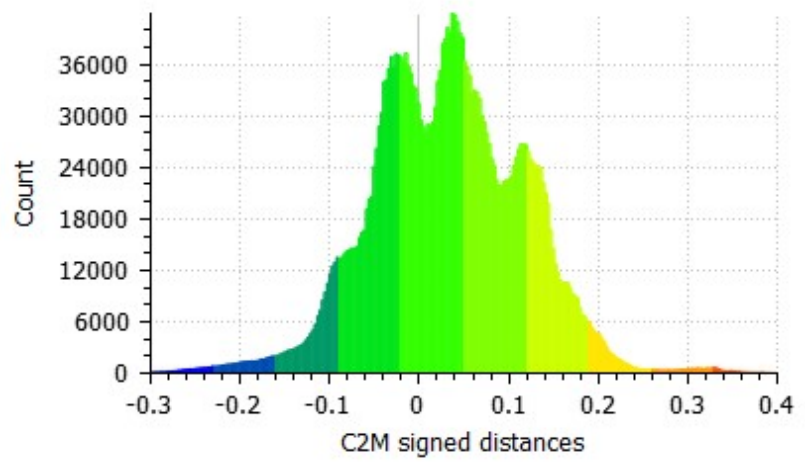

Figure 13. The distances between the point cloud and the mesh in the first comparison, expressed in $\mathrm{m}$.

Contrary of what shown before, the second comparison between an ideal vertical wall and the point cloud (Figure 14) highlighted the evident deviation of the top of the wall from a vertical plane. This considerable deviation reaches also values in the order of 30 to $45 \mathrm{~cm}$, evidencing the importance of a knowledge system able to highlight these and the historical matters. In fact, these aspects and the historical problems could be represented and taken into account in an information collector, such as an HBIM, to start forward-looking preserving activities for the safety of these kinds of Cultural Heritage. 


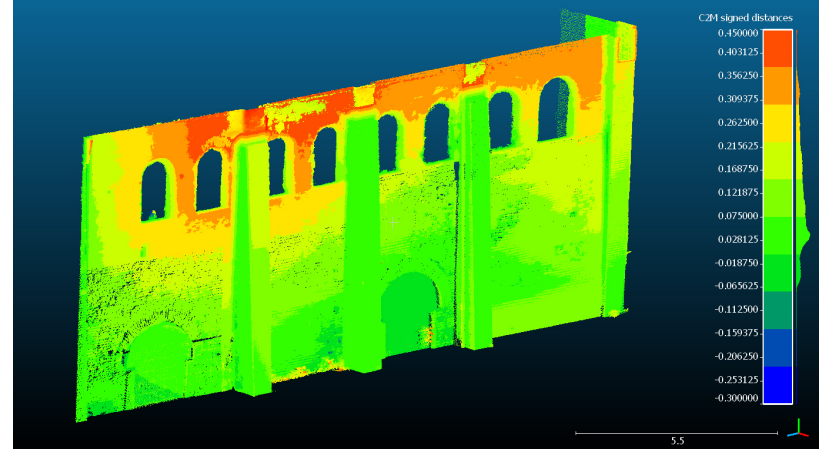

Figure 14. The second comparison: a vertical façade versus the point cloud.

Nevertheless, also the average distance (Figure 15), estimated in the order of $15 \mathrm{~cm}$, allows considering this kind of deviation not acceptable for a reasonable representation of the façade.

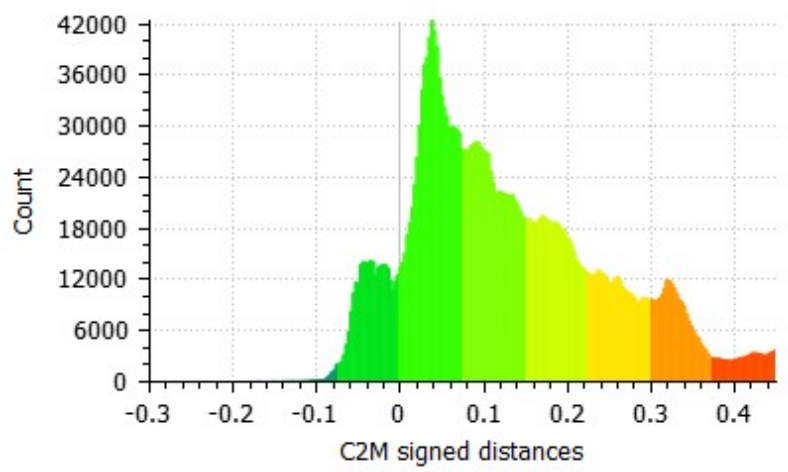

Figure 15. The distances between the point cloud and the mesh in the second comparison, expressed in $\mathrm{m}$.

\section{CONCLUSIONS}

In this paper, it was presented the capability of the modern Geomatics techniques to integrate each other and to obtain some 3D models useful for the development of an HBIM of an ancient cultural heritage building.

For this purpose, the procedure adopted for the development of the San Michele in Acerboli's church HBIM was shown and described. This product aimed at supporting the correct geometrical representation and the historical knowledge management for the architectural heritage conservation processes.

In fact, a collector of both the geometric and the historical information represents nowadays a useful instrument for all the operators involved in the management of these assets.

Nevertheless, this contribute tries also to offer a review to an effortless way to generate an irregular model of an ancient building in a widely used BIM software, such as Autodesk Revit, starting from 3D surveys data.

\section{ACKNOLEDGEMENTS}

The authors want to acknowledge the Municipality of Santarcangelo di Romagna, the Pro Loco office of the Municipality and the local Parish, for the kindly collaboration and for the support during the survey activities and the historical researches.

\section{REFERENCES}

Chiabrando, F., Sammartano, G., Spanò A., 2016. Historical Buildings Models and their Handling via 3D Survey: from Point Clouds to User-Oriented HBIM. The International Archives of the Photogrammetry, Remote Sensing and Spatial Information Sciences, Volume XLI-B5, pp. 633-640.

Dore, C., Murphy, M., 2012. Integration of Historic Building Information Modeling and 3D GIS for Recording and Managing Cultural Heritage Sites. In VSMM2012. Proceedings of the 18thInternational Conference on Virtual Systems and Multimedia. Virtual Systems in the Information Society, pp. 369-376.

Garagnani, S., Manfredini, A. M., 2013. Parametric accuracy: building information modeling process applied to the cultural heritage preservation, International Archives of the Photogrammetry, Remote Sensing and Spatial Information Sciences, Trento, Italy, Volume XL, Part 5/W1, pp. 88-92.

Lombardini, F., 2002. Pievi di Romagna, Il Ponte Vecchio, Cesena.

Mazzotti, M., 1961. Le pievi del Ravennate ad unica navata. In: VII Corso di cultura ravennate e bizantina, Ravenna.

Mazzotti, M., 1969. Nuove osservazioni sulle pievi di Sant'Arcangelo e di Barisano dopo gli ultimi lavori e scavi. In: VII Corso di cultura ravennate e bizantina, Ravenna.

Murphy, M., McGovern, E., Pavia, S., 2013. Historic Building Information Modelling - Adding intelligence to laser and image based surveys of European classical architecture, ISPRS Journal of Photogrammetry and Remote Sensing, 76, pp. 89102 .

Oreni, D., Brumana, R., Della Torre, S., Banfi, F., Barazzetti, L., Previtali, M., 2014. Survey turned into HBIM: the restoration and the work involved concerning the Basilica di Collemaggio after the earthquake (L'Aquila). ISPRS Annals of the Photogrammetry, Remote Sensing and Spatial Information Sciences, Volume II-5, pp. 267-273.

Pedretti, L. R., 1957. Archeologia e Miti in Santarcangelo di Romagna, Santarcangelo di Romagna.

Quattrini, R., Malinverni, E. S., Clini, P., Nespeca, R., Orlietti, E., 2015. From TLS to HBIM. High quality semantically-aware $3 d$ modeling of complex architecture, International Archives of the Photogrammetry, Remote Sensing and Spatial Information Sciences, Avila, Spain, Volume XL, Part 5/W4, pp. 367-374.

Remondino, F., 2011. Heritage Recording and 3D Modeling with Photogrammetry and $3 D$ Scanning. Remote Sensing, Vol. 3(6), pp.1104-1138.

Russo, E., 1983. La pieve di S. Michele Arcangelo a Santarcangelo di Romagna. In: Studi Romagnoli, XXXIV, Bologna.

Stoppioni, M. L., Fontana, P. A., Turci, M., Baratelli, A. M., 1999. Storia di Santarcangelo di Romagna, Il Ponte Vecchio, Cesena. 